\title{
The Protozoan Tetrahymena: Cellular Model for Biological Studies
}

\author{
Papa Daouda Mar $^{1}$, Bouchra El Khalfi ${ }^{1}$, Mounir Benyoussef ${ }^{2}$ \\ and Abdelaziz Soukri ${ }^{{ }^{*}}$ \\ ${ }^{1}$ Laboratory of Physiopathology, Molecular Genetics and Biotechnology (PGMB), Faculty of Sciences \\ Ain Chock, Hassan II University, Casablanca, Morocco. \\ ${ }^{2}$ Department of English, Faculty of Letters and Humanities, Hassan II University, Casablanca, \\ Morocco. \\ Authors' contributions \\ This work was carried out in collaboration among all authors. All authors read and approved the final \\ manuscript. \\ Article Information \\ DOI: 10.9734/ARRB/2019/v32i530095 \\ Editor(s): \\ (1) Dr. George Perry, Dean and Professor of Biology, University of Texas at San Antonio, USA \\ Reviewers: \\ (1) Sainudeen Pattazhy, University of Kerala, India. \\ (2) Mustafa Sevindik, Akdeniz University, Turkey. \\ (3) E. A. Adedoja, Achievers University, Nigeria. \\ Complete Peer review History: http://www.sdiarticle3.com/review-history/45579
}

Review Article

Received 28 September 2018

Accepted 04 December 2018 Published 08 August 2019

\begin{abstract}
Biological research, including clinical trials, mainly uses animals as model organisms. Currently, animal experimentation remains controversial for several reasons, namely the implementation of animal protection and ethics panels, the high costs and the long duration of experiments. These constraints encourage researchers to use alternative methods in order to overcome these barriers. The ciliate Tetrahymena is a unicellular eukaryotic organism that has contributed significantly to the acquisition of knowledge in the field of fundamental biology. Characterised by a well-ordered structure and a short life cycle, the protozoan Tetrahymena is very commonly used in the laboratory due to the ease involved in handling it. Therefore, this organism has allowed researchers to elucidate a number of mechanisms in higher organisms including mammals.

This bibliographic review describes the favourable biological characteristics of the protozoan Tetrahymena as well as various physiological and molecular studies that have been carried out on this organism. Studies have shown that Tetrahymena is one of the alternatives to animal experimentation and a major contributor to the development of biological and life sciences.
\end{abstract}


Keywords: Tetrahymena; cell model; structure; life cycle; physiological studies; molecular studies.

\section{INTRODUCTION}

Cellular model systems have a long history and are important tools for acquiring a great deal of knowledge in fundamental biology. Many structures and biological pathways have been discovered due to studies of well-explored model organisms $[1,2,3,4]$. The emergence of model organism studies stems from the fact that a multitude of biological mechanisms and structures are maintained across model organisms [5,6,7]. Historically, the most commonly used model organisms have been fungi and animals [8]. Indeed, these organisms are related to opisthokonts in much the same way as humans. Thus, this convergence encourages researchers to favor these organisms in order to respond to the complexity of the intracellular functioning of higher organisms. In this context, the yeast Saccharomyces cerevisiae is an example of an organism much in demand in biological studies, based on its ancestral relationship with humans.

However, a systematic approach with the same objective consists of the study of less-explored model organisms, coming from a different line of opisthokonts. Ciliates represent an attractive group of organisms to extend cellular biological studies to different lines. During their evolutionary history, ciliates have retained ancestral structures and functions that yeasts have lost, such as cilia and the regulation of the secretion of stored materials. Ciliated organisms have allowed the development of a wide range of experimental tools, namely the protozoa $T$. thermophila and Paramecium tetraurelia which are used to rigorously examine important biological issues $[9,10,11]$.

The protozoan Tetrahymena is a eukaryotic, mobile, and phagocytogenic unicellular organism commonly found in fresh and stagnant waters. In nature, they feed on bacteria while laboratory strains typically live in axenic cultures composed of nutrient-rich media or chemically defined media. These unicellular organisms are introduced to the laboratory at a very early stage because of their ease of culture in axenic media and the rapid growth of cells that divide every 2-3 hours under optimal conditions. The cells are wide, with a length between $30 \mu \mathrm{m}$ and $50 \mu \mathrm{m}$, ideal dimensions for studies under light and electron microscope. Like all ciliates,
Tetrahymena belongs to the group of alveolates that is part of the SAR clade (Stramenopiles Alveolata - Rhizaria). Tetrahymena belongs to the class of Oligohymenophorea and includes several morphologically indistinguishable species, among which we find the two best known species $T$. pyriformis and $T$. thermophila. Previously, these two species were grouped into a single species Tetrahymena geleii [12], later renamed Tetrahymena pyriformis. The discovery of mating patterns led to the separation of the group, based on sexual isolation, and identified $T$. thermophila as a distinct species [13]. The name "thermophila" is attributed to this species because it has an optimum growth temperature higher than the maximum temperature tolerated by $T$. pyriformis.

Tetrahymena has a long history distinguished by the discovery of major biological paradigms. $T$. thermophila is widely used in studies in cellular physiology and molecular genetics, $T$. pyriformis is also a very useful species in physiological and toxicological studies. Tetrahymena has a complex intracellular organisation and combines the biological complexity of higher organisms and the experimental accessibility of unicellular organisms. This organism uses many universally conserved eukaryotic processes, which also makes it useful for clarifying these conserved characteristics $[14,15]$.

As part of this review, we will focus on the structural configuration of the protozoan Tetrahymena. Secondly, we will review the essential characteristics of the cellular life cycle. Finally, we will devote a section to the studies in various fields in biology already carried out on the protozoan Tetrahymena, which have proven the credibility of this organism as a eukaryotic cellular model.

\section{TETRAHYMENA CELL STRUCTURE}

The protozoan Tetrahymena is a unicellular ciliate organism with a pear shape, approximately $50 \mu \mathrm{m}$ long and $20 \mu \mathrm{m}$ wide. It seems simple and small visually, but has a complex, orderly structural organisation at the cell surface [16]. Under the plasma membrane, eight distinct structural systems can be observed in an ordered network (Fig. 1) [17]. From the outside inward finds: cortical cells encased in a flattened membrane; 18 to 21 longitudinal 
microtubule groups; a continuous membrane skeleton (epiplasm); ciliated units (basal bodies); a network of dense nucleus secretory granules arranged longitudinally (mucocysts); a set of mitochondria aligned parallel to the rows of basal bodies and secretory granules; flattened sheets of endoplasmic reticulum; a network of small Golgi apparatus elements.

The cell has at its anterior end an oral cavity (cytostome) composed of four ("Tetra") ciliary units: an undulating membrane on the right and three membranelles on the left of the cavity. At the posterior end, we find the cytoproct which has excretory functions and two pores of the contractile vacuole. The latter, located at the distal part of the cell, plays a very important role in the osmotic regulation and empties through its two pores. The contractile vacuole is also involved in ionic balance. Cell cytoplasm is also distinguished by an enlarged phagosomal compartment in digestive vacuoles [18],
Mitochondria concentrated in the cellular cortex that provide aerobic respiration to the cell [19], a rough endoplasmic reticulum that suggests a role in the synthesis of membrane and secreted proteins similar to that of other eukaryotes [16], the Golgi apparatus associated with the endoplasmic reticulum [20] and peroxisomes which are sites of enzymatic activity such as catalase [21] and the $\beta$-oxidation of fatty acids [22].

Like all ciliates, Tetrahymena is characterised by a nuclear dimorphism that illustrates that the genome of the germ line and the somatic genome are located in two different nuclei: the micronucleus and the macronucleus respectively. The micronucleus is capable of mitosis and meiosis but is transcriptionally silent while the macronucleus is transcriptionally very active. This germinal-somatic separation is reminiscent of metazoans where the distinction between somatic cells and germ cells is maintained.
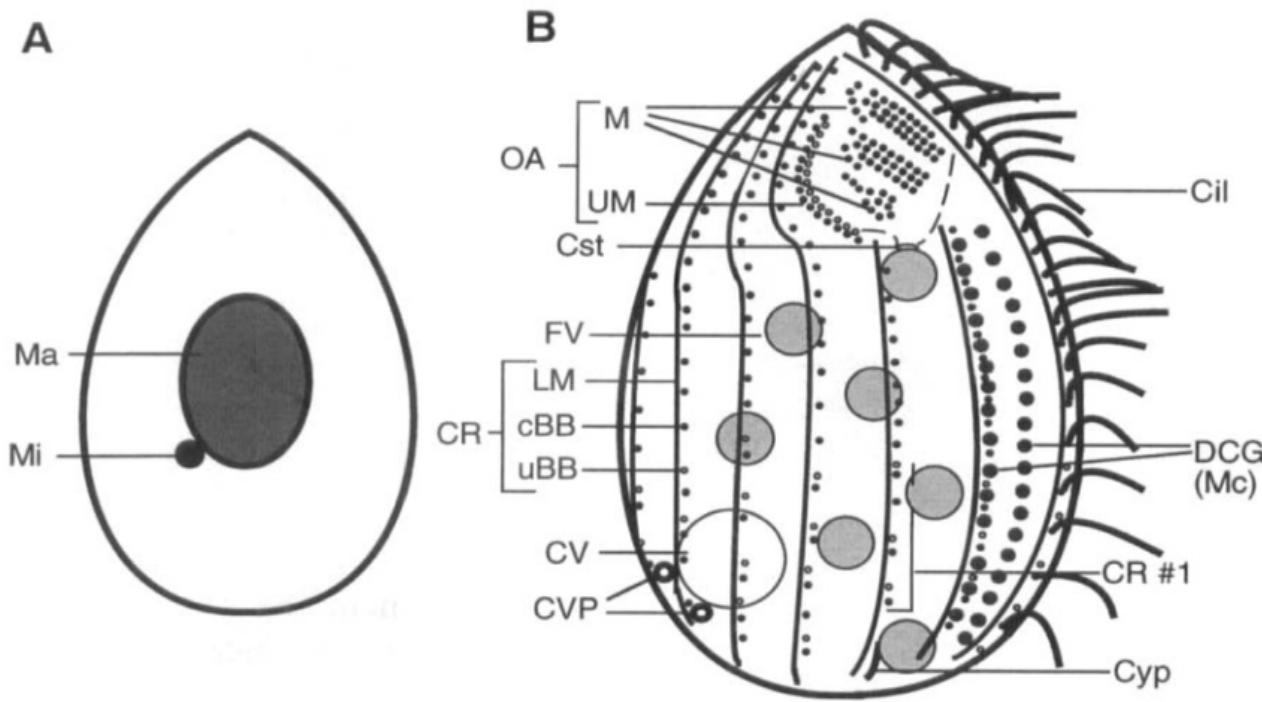

Fig. 1. Structural organisation of $T$. thermophila [17]

(A) Nuclear organisation. The cell has a germinal micronucleus (Mi) and a somatic macronucleus (Ma). (B) Cytoplasmic organisation seen from the ventral surface of the cell. Seven of the 18 to 21 ciliary rows (CR) are observed, with ciliated basal bodies (CBB) represented by closed points, uncapped basal bodies (UBB) in tiny open dots, groups of longitudinal microtubules (LM) represented by lines to the left (to the right of the cell) of the basal bodies. The cilia come from the $C B B s$ of one of the CRs and are omitted from the other rows. Dense nucleus secretory granules (DCG) are also called mucocysts (Mc). The three unique cortical landmarks are the oral apparatus (OA) on the anterior surface, the cytoproct (Cyp) and the contractile vacuolar pore (CVP) on the posterior surface. The Cyp is located at the right end of the cell of the two ciliary rows that terminate at the posterior end of the $O A$, which is arbitrarily designated as the reference row, the ciliary row no. 1 (CR \# 1). The basal bodies of the OA are organised into four structures composed of an undulating membrane (UM) and three membranelles (M). A mouth or cytostome (Cst) is located at the posterior end of the OA. Only one contractile vacuole (CV) empties through both CVPs. Food vacuoles (FV) are formed in the Cst and emptied at Cyp. 


\section{LIFE CYCLE OF THE PROTOZOAN TETRAHYMENA}

Like all ciliates, Tetrahymena is characterised by a germ line and a somatic line separated respectively into a micronucleus and a macronucleus. This separation specific to higher organisms is very rare in unicellular eukaryotes. To maintain these genomes and genetic diversity, the protozoan Tetrahymena uses both asexual (or vegetative) cell division and sexual reorganisation (or conjugation).

\subsection{Asexual Reproduction}

During vegetative division, the macronucleus is divided by random chromosomal segregation while the micronucleus is divided by mitosis, resulting in a binary fission (cytokinesis) of the parent cell into two daughter cells. However, vegetative reproduction is marked by significant changes from the cell surface to the nuclei. These changes begin with the morphogenesis of a new structure, future oral apparatus of the posterior daughter cell and perpendicular to the old oral apparatus (Fig. 2A, OP). This primitive structure then undergoes a complex process of development to form four ciliary structures: membranelles and an undulating membrane. An intermediate step is shown in Fig. 2B. When the primitive structure develops, new ciliary units are formed in the ciliary rows from a new probasal body anterior and perpendicular to the old. The membrane skeleton specific to basal bodies is formed as the new basal bodies take position in the cortex [23,24]. An equatorial subdivision of the cellular cortex occurs shortly before the start of cytokinesis (Fig. 2C), marked by the

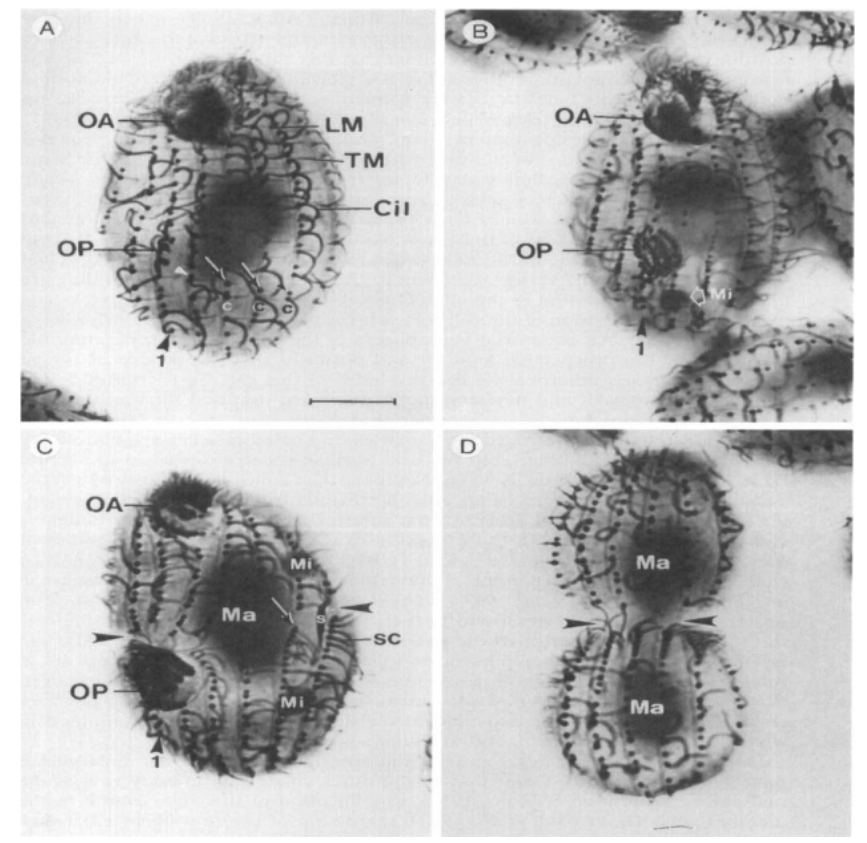

Fig. 2. Vegetative reproduction in the protozoan $T$. thermophila [17]. Scale bar: $10 \mu \mathrm{m}$

The anterior end is represented at the top of each figure; Figures (A), (B) and (C) are ventral view, Figure (D) is dorsal view. (A) Beginning of the development of the oral cavity. A new oral primitive device (OP "oral primordium") appears along the right ciliary row (1) posterior to the oral cavity (OA "oral apparatus"). In mature ciliary units (c), the basal bodies are associated with transverse microtubule groups (TM) and cilia (Cil). Immature ciliary units are observed at different stages of development. "Naked" basal bodies without TM or Cil (arrowheads) are located very close to mature ciliary units. Maturation units (arrows), with short TMs without cilia, are usually located farther from the parental ciliary units. LM: Iongitudinal band. (B) Advanced development of the oral cavity. Membranelles development in OP. The proliferation of the basal body along the ciliary rows continues. The micronucleus (Mi), close to the cell surface, is not yet divided. (C) Cell undergoing cortical division. The membranelles and the undulating membrane in OP are well developed. The oral cavity (OA) is simplified to look like OP. The fission zone is visible between the points of the arrows on a space in the form of a circumferential ring in the ciliary rows. The micronuclei have completed the division, although they are still connected by one or more strands containing the separation microtubules; Macronoyau (Ma) has just begun to divide. (D) The surface of a dividing cell. The macronoyau is divided. 


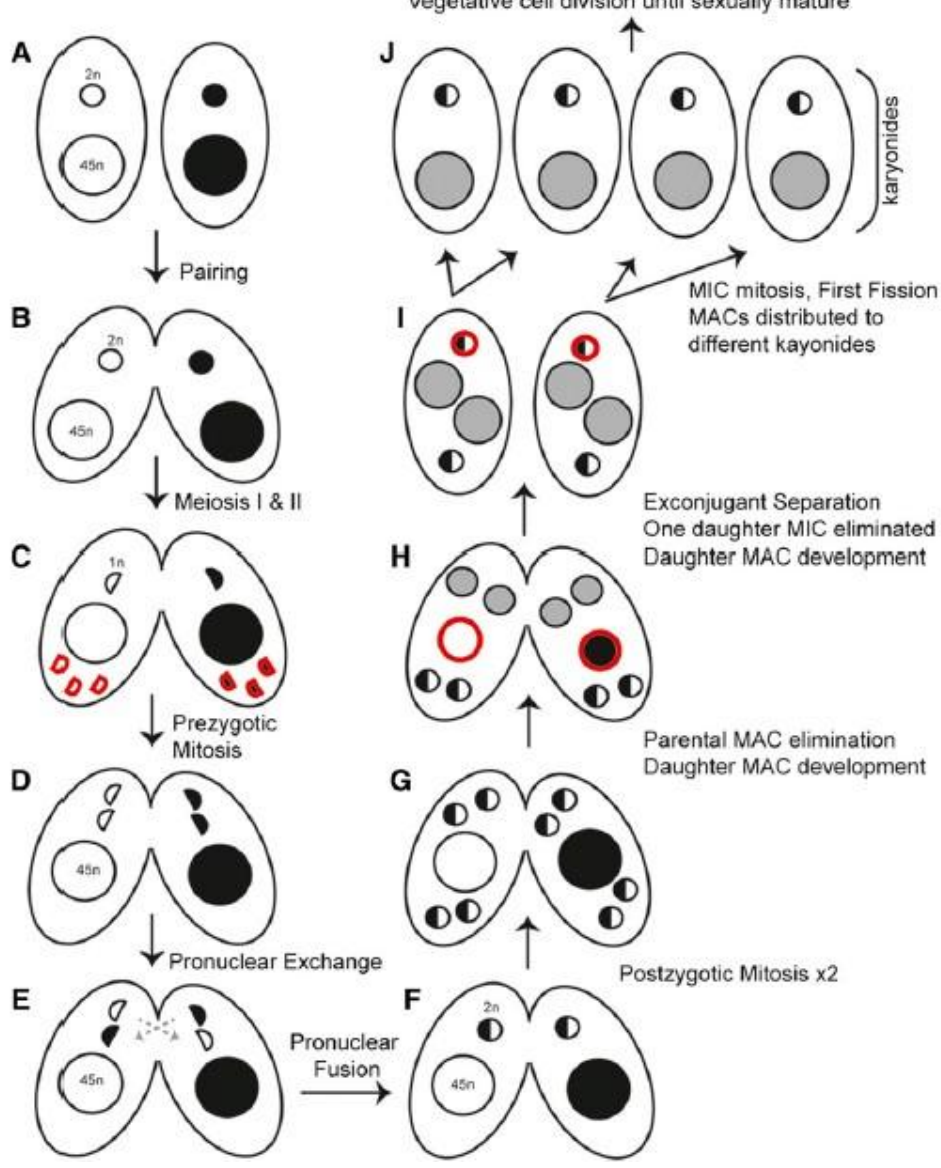

Fig. 3. Sexual reproduction (conjugation) in the protozoan Tetrahymena [13]

The cells are represented by ovals with a micronucleus (small circle) and a macronucleus (large circle) whose DNA content (ploidy) is indicated. The sexual phase of the life cycle begins with two cells of different types of mating $(A)$, homozygous for the black and white alleles, respectively, which undergo a pairing (B). The completion of two cycles of meiosis $(C)$ leads to the production of four haploid products (semicircles, indicated by $1 \mathrm{n}$ ). One of these meiotic products is positioned at the anterior cytoplasm of each conjugate, while the remaining three are targeted for elimination (red outline) at the posterior end of the conjugate. Subsequently, the mitosis of the surviving meiotic product generates two pronuclei of gametes (D). Each migratory pronucleus is transferred to the opposite conjugate in a process called pronuclear exchange (E). The incoming migratory pronuclei merge with the stationary pronuclei (pronuclear fusion), restoring the diploid character of the MIC and thus generating

the fertilisation nucleus (or zygote) (F). Thus, each fertilisation nucleus obtains a haploid genome from each parent (black and white semicircles). The nucleus of fertilisation undergoes two post-zygotic mitoses (G), leading to the production of four genetically identical diploid nuclei in each conjugate. (H) The two anterior nuclei develop into new MACs, while the two later nuclei become the new MICs. A new MAC maturation involves an increase in ploidy and a rearrangement of the programmed DNA. Parental MACs are removed by apoptosis (red outline) and do not provide DNA to the offspring. (I) The exconjugant cells separate and one of the two MICs is removed. When the exconjugants divide, one of the two fully developed MACs and a mitotic copy of the surviving MIC in each exconjugant are separated from their daughter cells (karyonides) because each receives an independently developed MAC (J). Once the process of conjugation is complete, these cells must mature sexually by vegetative cell division before they can conjugate.

appearance of an equatorial cleft in the ciliary rows separating any products of the anterior and posterior division. The cortical organisation is asymmetrical on the side of the cleft and just in front of the cleft; a new cytoproct and new contractile vacuoles are formed, destined for the posterior extremities of the former daughter cell. The most important event of the cortical cycle is cytokinesis (Fig. 2D). The anterior and posterior oral apparatuses complete their development 
synchronously. At this time, the micronucleus begins to divide which ends before the initiation of cytokinesis (Fig. 2C). The macronucleus division begins at the end of the micronucleus division [25] and ends in the midst of cytokinesis (Fig. 2D).

\subsection{Sexual Reproduction}

In the absence of sufficient food for vegetative reproduction, the cells engage in a sexual reproduction called conjugation. Conjugation is a process involving pairs of cells with a different mating pattern and is characterised by micronucleus meiosis, gametogenesis, and nuclei fusion to form the zygote nuclei (Fig. 3). The zygotic nuclei divide by mitosis to differentiate into a new micronucleus (MIC), and a new macronucleus (MAC), the MAC of each conjugant is destroyed (Fig. 3). Conjugation is very important because it allows an increase in genetic diversity.

\section{TETRAHYMENA AS
ORGANISM FOR RESEARCH}

\subsection{Toxicological}

The protozoan Tetrahymena has been widely used by many researchers to evaluate the toxic potential of xenobiotics in the environment, but also of drugs and water quality. A number of studies were carried out by measuring different physiological parameters such as kinetic growth, cell density, morphology, mobility and cellular biomarkers. Under optimal conditions, the growth of Tetrahymena is characterised by a lag phase, an exponential phase and a stationary phase. This behaviour can be utilised for toxicological tests. Generally, the cell density is determined automatically by an electronic particle counter or under a microscope by a hemocytometer. Tetrahymena is also distinguished by changes in morphology and mobility in the presence of toxic agents, as well as a change in the expression of biomarkers that are highly sought after in toxicological studies.

\subsection{Environmental Pollutants}

Environmental pollutants have long-term effects on cellular development and pose a threat to public health. Several diseases are detected in humans through chronic exposure to pollutants generally contained in food and drinking water. For decades, several studies have been conducted on the protozoan Tetrahymena as a model organism to understand and combat the mechanistic impact of various pollutants. Several authors have worked on the protozoa to study the toxic effect of heavy metals, including arsenic and cadmium, for example $[26,27,28]$.

Arsenic is a toxic element found in the environment which causes a number of diseases such as cancer and diabetes [29,30]. Arsenic exposure at IC50 concentration is shown to cause damage to the growth, shape and mobility of $T$. pyriformis [28]. On the other hand, at moderate concentration, the organism adapts in the long term through metal detoxification and thus constitutes a pillar for studying the metabolic pathways involved in this detoxification process. Cadmium is also a toxic element that can be found in food and drinking water. Larsen's studies have shown that cadmium sensitivity is proportional to the exponential phase density of T. pyriformis while the sensitivity decreases to the stationary phase due to cell adaptation in the presence of metal [26]. Other studies have shown an inhibition of the activity, protein expression and kinetic parameters of the mitochondrial biomarker $D$ - $\beta$-hydroxybutyrate in T. pyriformis [27].

Aluminum is one of the most abundant elements in the environment. It is naturally present in water and involved in neurodegenerative diseases in humans [31] and increased mortality in aquatic organisms [32]. These facts were verified in the protozoan $T$. pyriformis, which showed dosedependent growth and mobility, solubility of aluminum and a chelator coupled with metal [33].

\subsection{Pharmaceutical Products}

The use of drugs requires prior knowledge about the toxic concentrations and side effects of these products. In this sense chemotaxis of Tetrahymena is used in several studies to estimate the toxic effect of drugs. Studies have tested the toxic effect of extracts of a medicinal plant, Ginkgo biloba L. , on the PKG protein that controls the chemotaxis of the protozoa $T$. thermophila by adjusting ciliary beats [34]. These extracts exerted a significant inhibition of chemotaxis and PKG activity in T. thermophila cells.

A contributive study showed the mechanism of inhibition of the cellular model $T$. thermophila by shiga-toxins [35]. These products are secreted by certain virulent bacteria and cause diseases in 
mammals [36]. Inhibition of protozoan growth by these substances has been blocked by mutations preventing bacterial response or by enzymes which degrade the hydrogen peroxide produced by the protozoan. Hydrogen peroxide signals the presence of the protozoan leading to the induction of bacteriophages and the production of shiga toxins.

Researchers have focused on pharmaceuticals contaminating aquatic environments by testing the toxic effect of several pharmaceuticals on the growth and shape of the protozoa T. pyriformis [37]. These studies suggest that the protozoan Tetrahymena is a model organism for analysing aquatic contaminants and understanding the mechanisms involved in toxicity by measuring more specific parameters.

\subsection{Oxidative Stress}

Oxidative stress is a process that is involved in the deterioration of several cellular components such as structure, nucleic acids, proteins and lipids [38,39], that can compromise health and cell viability leading to necrotic or apoptotic cell death $[40,41,42]$. Oxidative stress is involved in many diseases such as cancer $[43,44]$ and neurodegenerative diseases $[45,46]$. Studies have shown that oxidative stress induced by hydrogen peroxide or nitric oxide inhibits growth and changes the shape of protozoa $T$. thermophila and T. pyriformis $[47,48]$. Molecular studies have also shown a modification of the activity of antioxidant enzymes (superoxide dismutase and catalase) and a regulation of the GAPDH enzyme which is essential for cellular metabolism [47]. It's aso shown that oxidative stress induced by hydrogen peroxide causes a decrease of cell growth correlated with an activation of mammalian apoptotic signal kinase1 (MAPKK) [49].

The protozoan T. pyriformis has also been used to study the involvement of iron in Alzheimer's disease [50]. Iron has been shown to have adverse effects on the central nervous system by causing the formation of highly toxic free radicals [51]. Iron chelation therapy is in great demand to treat iron overload related diseases, but the use of currently available chelators to remove iron from the brain is limited because of their toxicity and / or poor transfer across the blood-brain barrier [52]. In the search for new alternatives, the chelating effect of different compounds of the Opuntia ficus-indica (L.) Mill. plant such as resveratrol are tested on the protozoan
Tetrahymena pyriformis by following the viability, density and morphology of the cells. The results of this study showed that iron accumulates in this protozoan and that this accumulation is responsible for the decrease in viability and cellular activity. The evaluation of stress markers shows that iron induces high production of catalase, superoxide dismutase and glutathione peroxidase. The application of $O$. ficus-indica extracts showed protection of cells against iron toxicity and a return to normal cellular activity. Morphological visualisation has also shown the ability of plant extracts and metabolites to prevent the accumulation of iron.

A variety of antioxidant supplements have been developed in recent years to enrich the endogenous defense systems of living organisms. However, the prevention of chronic diseases through the use of antioxidant supplements remains controversial [53]. In the search for new alternatives, a recent study has shown the protective effect of the essential oils of Salvia officinalis L. and Origanum vulgare L. against the oxidative stress induced by hydrogen peroxide and sodium nitroprusside in the two species T. thermophila and T. pyriformis [54]. Growth, morphology, and cell density were monitored in this study, and the results showed that oxidative stress inhibits growth, cell density, and changes the shape of both species. The application of the oils has shown protection of the peroxide-treated cells which regain normal growth and morphology, whereas the cells treated with sodium nitroprusside (nitric oxide donor) return to a normal form but their growth remains slowed because this stressor modifies the expression of certain proteins essential for cellular metabolism $[55,56]$.

\subsection{Genetic}

Tetrahymena is a eukaryotic cell that provides tools and techniques for discovering new genes and revealing the presence of important molecular mechanisms behind these genes. It is a unicellular organism that combines the biological complexity of higher organisms with accessibility in classical and reverse genetics [13]. It is in this sense that Hennessey and Lampert studied the physiological behavior of Tetrahymena to estimate the effect of genetic mutations [57]. They performed experiments that can be used in both classical and reverse genetics approaches to better understand the cellular functions of genotype to phenotype [57]. 
Characterised by nuclear dimorphism, Tetrahymena helps to elucidate germinal and somatic differentiation. The work done on Tetrahymena led to major discoveries such as dynein, the first engine of microtubules [58], the discovery of catalytic RNA [59] and the structure of telomeres and telomerases [60] which have each earned a Nobel Prize. Tetrahymena also enabled the discovery the enzyme "histone acetyltransferase" which plays an important role in histone modification and transcriptional regulation, which gave rise to histone coding and epigenetic control of gene expression by chromatin modification [61]. These discoveries have transformed Tetrahymena into a highly beneficial experimental organism that is essential for addressing a wide range of biological problems. Among the genetic advantages of Tetrahymena is also the ability to explore the role of deleterious or lethal recessive mutations, which can propagate to the homozygous state in the transcriptionally silent germline $[62,63]$. Turkewitz and colleagues have described different methods that can be used for efficient cellular transformation through DNA [11].

\subsection{Hormone Receptors}

The ciliate Tetrahymena has a set of hormone receptors found in higher organisms, particularly insulin, ACTH, histamine, serotonin, etc. These hormones are chemically and functionally very similar to those of mammals and play an important role in mobility, phagocytosis, chemotaxis and growth of the protozoan Tetrahymena [64]. Previous work has shown that stress conditions (starvation, high temperature, high salt concentration, formaldehyde, alcohol) increase the intracellular level of the ACTH, endorphin, serotonin and T3 hormones produced by Tetrahymena $[65,66,67]$. Other studies have shown that copper poisoning or treatment with parachlorophenylalanine (tryptophan hydrolase inhibitor) increases intracellular secretion of the hormones epinephrine, insulin and histamine [65].

A recent study has shown that Tetrahymena is able to use lectins to influence sexual reproduction, stimulate hormonal receptors, imitate hormonal functions, influence phagocytosis, cell movement and cell division [68]. Lectins are proteins found in plants and animals and are used to diagnose sugars in solutions or on the surface of cells, as well as in the study of blood groups. These proteins are involved in research in cell biology, membrane structure, innate immunity, cancer, infections and genetic engineering $[69,70,71]$.

\section{CONCLUSION}

This review has shown that a wide array of discoveries have been made by researchers thanks to the benefits provided by the protozoan Tetrahymena. The latter has several physiological (growth, morphology, mobility, density), genetic (germ line and somatic line) and molecular (biomarkers) parameters that present an opportunity to harness this organism as a model in toxicological, molecular and physiological research. Thus, use of the protozoan Tetrahymena can be considered an essential approach to answering the problems related to the complex intracellular functioning of higher organisms.

\section{COMPETING INTERESTS}

Authors have declared that no competing interests exist.

\section{REFERENCES}

1. Boehm M, Bonifacino JS. Genetic analyses of adaptin function from yeast to mammals. Gene. 2002;286(2):175-86.

2. Kimble J. Molecular regulation of the mitosis/meiosis decision in multicellular organisms. Cold Spring Harb Perspect Biol. 2011;3:8.

Available:https://doi.org/10.1101/cshpersp ect.a002683

3. Kourtis N, Tavernarakis N. Autophagy and cell death in model organisms. Cell Death Differ. 2009;16(1):21-30.

Available:https://doi.org/10.1038/cdd.2008. 120

4. Westermann B. Mitochondrial dynamics in model organisms: What yeasts, worms and flies have taught us about fusion and fission of mitochondria. Semin Cell Dev Biol. 2010;21(6):542-9.

Available:https://doi.org/10.1016/j.semcdb. 2009.12.003

5. Ashburner M, Ball CA, Blake JA, Botstein $D$, Butler $H$, Cherry JM, et al. Gene ontology: Tool for the unification of biology. Nature Genetics; 2000.

Available:https://doi.org/10.1038/75556

6. Gönczy P. Mechanisms of asymmetric cell division: Flies and worms pave the way. Nat Rev Mol Cell Biol. 2008;9(5):355-66. 
Available:https://doi.org/10.1038/nrm2388

7. Simons M, Mlodzik M. Planar cell polarity signaling: From fly development to human disease. Annu Rev Genet. 2008;42:51740.

Available:https://doi.org/10.1146/annurev.g enet.42.110807.091432

8. Davis RH. The age of model organisms. Nat Rev Genet. 2004;5(1):69-76.

Available:https://doi.org/10.1038/nrg1250

9. Beisson J, Bétermier M, Bré MH, Cohen J, Duharcourt S, Duret L, et al. Paramecium tetraurelia: The renaissance of an early unicellular model. Cold Spring Harb Protoc. 2010;(1):pdb.emo140.

Available:https://doi.org/10.1101/pdb.emo1 40

10. Collins K, Gorovsky MA. Tetrahymena thermophila. Curr Biol CB. 2005;15(9): R317-318.

Available:https://doi.org/10.1016/j.cub.200 5.04.039

11. Turkewitz AP, Orias E, Kapler G. Functional genomics: The coming of age for Tetrahymena thermophila. Trends Genet TIG. 2002;18(1):35-40.

12. Furgason $\mathrm{W}$. The significant cytostomal pattern of the "Glaucoma-Colpidium" group and a proposed new genus and species, Tetrahymena geleii. Arch Für Protistenkd. 1940;94:224-66.

13. Ruehle MD, Orias E, Pearson CG. Tetrahymena as a unicellular model eukaryote: Genetic and genomic tools. Genetics. 2016;203(2):649-65.

Available:https://doi.org/10.1534/genetics. 114.169748

14. Briguglio JS, Turkewitz AP. Tetrahymena thermophila: A divergent perspective on membrane traffic. J Exp Zoolog B Mol Dev Evol. 2014;322(7):500-16.

Available:https://doi.org/10.1002/jez.b.225 64

15. Lynch M, Field MC, Goodson HV, Malik HS, Pereira-Leal JB, Roos DS, et al. Evolutionary cell biology: Two origins, one objective. Proc Natl Acad Sci. 2014; 111(48):16990-4.

Available:https://doi.org/10.1073/pnas.141 5861111

16. Satir BH, Wissig SL. Alveolar sacs of Tetrahymena: Ultra structural characteristics and similarities to subsurface cisterns of muscle and nerve. J Cell Sci. 1982;55: 13-33.
17. Frankel J. Cell biology of Tetrahymena thermophila. Methods Cell Biol. 2000;62: 27-125.

18. Nilsson JR. Phagotrophy in Tetrahymena. In: Biochemistry and physiology of protozoa. Academy Press. New York: Levandowsky M \& Hutner SH. 1979;33979.

19. Aufderheide K. Mitochondrial associations with specific micro tubular components of the cortex of Tetrahymena thermophila. I. Cortical patterning of mitochondria. J Cell Sci. 1979;39:299-312.

20. Franke WW, Eckert WA, Krien S. Cytomembrane differentiation in a ciliate, Tetrahymena pyriformis. I. Endoplasmic reticulum and dictyosomal equivalents. Z Zellforsch Mikrosk Anat Vienna Austria 1948. 1971;119(4):577-604.

21. Müller $M$, Baudhuin $P$, De Duve $C$. Lysosomes in Tetrahymena pyriformis. I. Some properties and lysosomal localization of acid hydrolases. J Cell Physiol. 1966;68(2):165-75.

Available:https://doi.org/10.1002/jcp.10406 80211

22. Müller M, Hogg JF, Duve C de. Distribution of tricarboxylic acid cycle enzymes and glyoxylate cycle enzymes between mitochondria and peroxisomes in Tetrahymena pyriformis. J Biol Chem. 1968;243(20):5385-95.

23. Kaczanowska J, Buzanska L, Ostrowski M. Relationship between spatial pattern of basal bodies and membrane skeleton (epiplasm) during the cell cycle of Tetrahymena: cdaA mutant and antimembrane skeleton immunostaining. J Eukaryot Microbiol. 1993;40(6):747-54.

24. Williams NE, Honts JE, Kaczanowska J. The formation of basal body domains in the membrane skeleton of Tetrahymena. Dev Camb Engl. 1990;109(4):935-42.

25. Jaeckel-Williams R. Nuclear divisions with reduced numbers of microtubules in Tetrahymena. J Cell Sci. 1978;34:303-19.

26. Larsen J. The influence of growth phase and culture conditions of Tetrahymena on effects of cadmium. Toxicology. 1989; 58(2):211-23.

27. Mountassif D, Kabine $M$, Manar R, Bourhim N, Zaroual Z, Latruffe N, et al. Physiological, morphological and metabolic changes in Tetrahymena pyriformis for the in vivo cytotoxicity assessment of metallic pollution: Impact on d- $\beta$-hydroxybutyrate 
dehydrogenase. Ecol Indic. 2007;7(4):88294.

Available:https://doi.org/10.1016/j.ecolind.2 006.11 .010

28. Zhang YY, Yang J, Yin XX, Yang SP, Zhu YG. Arsenate toxicity and stress responses in the freshwater ciliate Tetrahymena pyriformis. Eur J Protistol. 2012;48(3):22736.

Available:https://doi.org/10.1016/j.ejop.201 2.01 .005

29. Kapaj S, Peterson H, Liber K, Bhattacharya P. Human health effects from chronic arsenic poisoning- A review. J Environ Sci Health Part A Tox Hazard Subst Environ Eng. 2006;41(10):2399428.

Available:https://doi.org/10.1080/10934520 600873571

30. Tchounwou PB, Centeno JA, Patlolla AK. Arsenic toxicity, mutagenesis, and carcinogenesis-A health risk assessment and management approach. Mol Cell Biochem. 2004;255(1-2):47-55.

31. Savory J, Exley C, Forbes WF, Huang Y, Joshi JG, Kruck $T$, et al. Can the controversy of the role of aluminum in Alzheimer's disease be resolved? What are the suggested approaches to this controversy and methodological issues to be considered? J Toxicol Environ Health. 1996;48(6):615-35.

32. Sparling DW, Lowe TP. Environmental hazards of aluminum to plants, invertebrates, fish, and wildlife. In: Reviews of Environmental Contamination and Toxicology. Springer. New York. 1996;1127.

Available:https://doi.org/10.1007/978-14612-2354-2_1

33. Sauvant MP, Pepin D, Bohatier J, Groliere CA. Effects of chelators on the acute toxicity and bioavailability of aluminium to Tetrahymena pyriformis. Aquat Toxicol. 2000;47(3):259-75.

Available:https://doi.org/10.1016/S0166445X(99)00015-6

34. Chen F, Leick V. The protozoan Tetrahymena as a bioindicator to screen bioactive substances. J Microbiol Methods. 2004;59(2):233-41.

Available:https://doi.org/10.1016/j.mimet.2 004.07.003

35. Lainhart W, Stolfa G, Koudelka GB. Shiga toxin as a bacterial defense against a eukaryotic predator, Tetrahymena thermophila. J Bacteriol. 2009;191(16): 5116-22.

Available:https://doi.org/10.1128/JB.0050809

36. Brüssow H, Canchaya C, Hardt WD. Phages and the evolution of bacterial pathogens: From genomic rearrangements to lysogenic conversion. Microbiol Mol Biol Rev MMBR. 2004;68(3):560-602.

Available:https://doi.org/10.1128/MMBR.68 .3.560-602.2004

37. Láng J, Köhidai L. Effects of the aquatic contaminant human pharmaceuticals and their mixtures on the proliferation and migratory responses of the bioindicator freshwater ciliate Tetrahymena. Chemosphere. 2012;89(5):592-601.

Available:https://doi.org/10.1016/j.chemosp here.2012.05.058

38. Errafiy N, Soukri A. Purification and partial characterization of glyceraldehyde-3phosphate dehydrogenase from the ciliate Tetrahymena thermophila. Acta Biochim Biophys Sin. 2012;44(6):527-34.

Available:https://doi.org/10.1093/abbs/gms 028

39. Maes M, Mihaylova I, Kubera M, Uytterhoeven M, Vrydags N, Bosmans $\mathrm{E}$. Increased 8-hydroxy-deoxyguanosine, a marker of oxidative damage to DNA, in major depression and myalgic encephalomyelitis / chronic fatigue syndrome. Neuro Endocrinol Lett. 2009; 30(6):715-22.

40. Flora SJ. Structural, chemical and biological aspects of antioxidants for strategies against metal and metalloid exposure. Oxid Med Cell Longev. 2009; 2(4):191-206.

41. Valko M, Leibfritz D, Moncol J, Cronin MTD, Mazur M, Telser J. Free radicals and antioxidants in normal physiological functions and human disease. Int $\mathrm{J}$ Biochem Cell Biol. 2007;39(1):44-84.

42. Veal EA, Day AM, Morgan BA. Hydrogen peroxide sensing and signaling. Moll Cel. 2007;26:1-14.

43. Sevindik M. Investigation of oxidant and antioxidant status of edible mushroom Clavariadelphus truncatus. Mantar Dergisi. 2018;9(2):165-168.

44. Gerber M, Boutron-Ruault MC, Hercberg S, Riboli E, Scalbert A, Siess MH. Food and cancer: State of the art about the protective effect of fruits and vegetables. Bull Cancer (Paris). 2002;89(3):293-312. 
45. Kohen R, Nyska A. Oxidation of biological systems: Oxidative stress phenomena, antioxidants, redox reactions, and methods for their quantification. Toxicol Pathol. 2002;30(6):620-50.

Available:https://doi.org/10.1080/01926230 290166724

46. Huang WJ, Zhang X, Chen WW. Role of oxidative stress in Alzheimer's disease. Biomed Rep. 2016;4(5):519-522.

Available:https://doi.org/10.3892/br.2016.6 30

47. Errafiy N, Ammar E, Soukri A. Protective effect of some essential oils against oxidative and nitrosative stress on Tetrahymena thermophila growth. J Essent Oil Res. 2013;25(4):339-47.

Available:https://doi.org/10.1080/10412905 .2013.775681

48. Fourrat L, Iddar A, Valverde F, Serrano A, Soukri A. Effects of oxidative and nitrosative stress on Tetrahymena pyriformis glyceraldehyde-3-phosphate dehydrogenase. J Eukaryot Microbiol. 2007;54(4):338-46.

Available:https://doi.org/10.1111/j.15507408.2007.00275.x

49. Li W, Zhang S, Numata O, Nozama Y, Wang S. Tp MRK regulates cell division of Tetrahymena in response to oxidative stress. Cell Biochem Funct. 2009;27(6): 364-369.

50. Available:https://doi.org/10.1002/cbf.1583.

Karym EM. Impacts d'antioxydant naturels sur la neurodégénérescence induite par des acides gras à très longue chaine: Aspects biochimiques et métaboliques; 2016.

[Accessed 8 June 2018]

Available:http://www.theses.fr/s101404

51. Farina M, Avila DS, da Rocha JBT, Aschner M. Metals, oxidative stress and neurodegeneration: A focus on iron, manganese and mercury. Neurochem Int. 2013;62(5):575-94.

Available:https://doi.org/10.1016/j.neuint.2 012.12 .006

52. Richardson N. The therapeutic potential of iron chelators. Expert Opin Investig Drugs. 1999;8(12):2141-58.

Available:https://doi.org/10.1517/13543784 8.12.2141

53. Kurutas EB. The importance of antioxidants which play the role in cellular response against oxidative/nitrosative stress: current state. Nutr J. 2016;15(1): 71.
Available:https://doi.org/10.1186/s12937016-0186-5

54. Mar PD, El Khalfi B, Soukri A. Protective effect of oregano and sage essentials oils against the effect of extracellular $\mathrm{H} 2 \mathrm{O} 2$ and SNP in Tetrahymena thermophila and Tetrahymena pyriformis. J King Saud Univ - Sci; 2018.

Available:https://doi.org/10.1016/j.jksus.20 18.05.005

55. Wink DA, Mitchell JB. Chemical biology of nitric oxide: insights into regulatory, cytotoxic, and cytoprotective mechanisms of nitric oxide. Free Radic Biol Med. 1998; 25(4-5):434-56.

Available:https://doi.org/10.1016/S08915849(98)00092-6

56. Zou M, Yesilkaya A, Ullrich V. Peroxynitrite inactivates prostacyclin synthase by heme-thiolate-catalyzed tyrosine nitration. Drug Metab Rev. 1999;31(2):343-9. Available:https://doi.org/10.1081/DMR100101922

57. Hennessey TM, Lampert TJ. Chapter 15 behavioral bioassays and their uses in Tetrahymena. In: Collins $\mathrm{K}$, editor. Methods in Cell Biology. Academic Press. 2012;109:393-410.

Available:https://doi.org/10.1016/B978-012-385967-9.00015-3

58. Gibbons IR, Rowe AJ. Dynein: A protein with adenosine Triphosphatase activity from cilia. Science. 1965;149(3682):424-6. Available:https://doi.org/10.1126/science.1 49.3682.424

59. Kruger K, Grabowski PJ, Zaug AJ, Sands $J$, Gottschling DE, Cech TR. Self-splicing RNA: Autoexcision and autocyclization of the ribosomal RNA intervening sequence of Tetrahymena. Cell. 1982;31(1):147-57.

60. Greider CW, Blackburn EH. Identification of a specific telomere terminal transferase activity in Tetrahymena extracts. Cell. 1985;43:405-13.

61. Brownell JE, Zhou J, Ranalli T, Kobayashi $\mathrm{R}$, Edmondson DG, Roth SY, et al. Tetrahymena histone acetyltransferase A: a homolog to yeast Gcn5p linking histone acetylation to gene activation. Cell. 1996; 84(6):843-51.

62. Allen SL. Genomic exclusion: A rapid means for inducing homozygous diploid lines in Tetrahymena pyriformis, syngen 1. Science. 1967;155(3762):575-7.

63. Hamilton EP, Suhr-Jessen PB, Orias E. Pronuclear fusion failure: An alternate conjugational pathway in Tetrahymena 
thermophila, induced by vinblastine. Genetics. 1988;118(4):627-36.

64. Csaba G. The hormonal system of the unicellular Tetrahymena: A review with evolutionary aspects. Acta Microbiol Immunol Hung. 2012;59(2):131-56.

Available:https://doi.org/10.1556/AMicr.59. 2012.2.1

65. Csaba G, Kovács P, Pállinger É. Effect of starvation on insulin production and insulin binding in Tetrahymena. Cell Biochem Funct. 2007;25(4):473-477.

Available:https://doi.org/10.1002/cbf.1333

66. Csaba G, Kovács P, Pállinger E. Increased hormone levels in Tetrahymena after longlasting starvation. Cell Biol Int. 2007;31(9): 924-928.

Available:https://doi.org/10.1016/j.cellbi.20 07.02.007

67. Csaba G, Pállinger E. How applicable is the general adaptation syndrome to the unicellular Tetrahymena? Cell Biochem Funct. 2009;27(1):12-5.
Available:https://doi.org/10.1002/cbf.1527

68. Csaba G. Lectins and Tetrahymena - A review. Acta Microbiol Immunol Hung. 2016;63(3):279-91.

Available:https://doi.org/10.1556/030.63.20 16.001

69. Endriga MA, Mojica ERE, Merca FE, Lacsamana MS, Deocaris CC. Evaluation of some lectins as anti-protozoal agents. J Med Sci. 2005;5(1):31-4.

Available:https://doi.org/10.3923/jms.2005. 31.34

70. Hébert E. Endogenous lectins as cell surface transducers. Biosci Rep. 2000; 20(4):213-37.

Available:https://doi.org/10.1023/A:102648 4722248

71. Ip WKE, Takahashi K, Ezekowitz RA, Stuart LM. Mannose-binding lectin and innate immunity. Immunol Rev. 2009; 230(1):9-21.

Available:https://doi.org/10.1111/j.1600065X.2009.00789.X

(c) 2019 Mar et al.; This is an Open Access article distributed under the terms of the Creative Commons Attribution License (http://creativecommons.org/licenses/by/4.0), which permits unrestricted use, distribution, and reproduction in any medium, provided the original work is properly cited.

Peer-review history:

The peer review history for this paper can be accessed here: http://www.sdiarticle3.com/review-history/45579 